\title{
Graduated compression stockings
}

\author{
Chung Sim Lim MBBS PhD, Alun H. Davies DM
}

$\longrightarrow$ ompression therapy is a frequently used physical therapy in conditions involving venous and lymphatic insufficiency in the lower limbs, including varicosities, lymphedema, venous eczema and ulceration, deep vein thrombosis and postthrombotic syndrome. The many forms of compression therapy include elastic and nonelastic bandages, boots, hosiery or stockings (Box 1), and pneumatic devices. ${ }^{1}$ Graduated compression stockings (Figure 1) are often prescribed and have the advantage of being more acceptable, relatively easier to put on and less cumbersome than bandaging and pneumatic devices. However, not all patients tolerate graduated compression stockings, and problems with compliance are not uncommon.

We review the current evidence of the therapeutic roles of graduated compression stockings and the problems associated with their use. The evidence used in this review is described in Box 2 .

\section{What are the mechanisms of action of compression stockings?}

Figure 2 summarizes the mechanisms of action of graduated compression stockings. The stockings work by exerting the greatest degree of compression at the ankle, with the level of compression gradually decreasing up the garment. The pressure gradient ensures that blood flows upward toward the heart instead of refluxing downward to the foot or laterally into the superficial veins. The application of adequate graduated compression reduces the diameter of major veins, which increases the velocity and volume of blood flow. ${ }^{2}$ Graduation compression can reverse venous hypertension, augment skeletal-muscle pump, facilitate venous return and improve lymphatic drainage. ${ }^{3}$ It also initiates complex physiologic and biochemical effects involving the venous, arterial and lymphatic systems, although the exact mechanisms remain unclear. ${ }^{2,45}$ One study that used near-infrared spectroscopy to monitor changes in tissue oxyhemo globin and deoxyhemoglobin reported that limb oxygenation increased with the use of graduated compression stockings, especially with highcompression stockings. ${ }^{4}$ Another study showed that levels of proinflammatory cytokines (e.g., interleukin- $1 \alpha$, interleukin- 6 and interferon- $\gamma$ ) in ulcer tissue in patients with active ulcers were significantly reduced following compression therapy. ${ }^{5}$

\section{How is the strength of compression graded?}

Graduated compression stockings are classified according to the sub-bandage compression pressure applied by the garment at the ankle level. The pressures are determined by the manufacturer based on laboratory measurements. The degree of pressure is classified into several standards. Unfortunately, there is no single standard used worldwide, which may cause confusion. In general, though, low compression refers to pressure of less than $20 \mathrm{~mm} \mathrm{Hg}$ or class 1 ; medium compression to pressure of 20 $30 \mathrm{~mm} \mathrm{Hg}$ or class 2; and high compression to pressure of greater than $30 \mathrm{~mm} \mathrm{Hg}$, or class 3 or higher. The overall pressure is affected by factors such as the elasticity and stiffness of stocking material, the size and shape of the wearer's legs, and the movements and activities of the wearer. ${ }^{6}$

\section{What are the problems associated with compression stockings?}

\section{Contraindications and complications}

The contraindications of graduated compression stockings are listed in Box $3 .^{6-9}$ The stockings are generally safe to use, with relatively few compli-
Competing interests: None declared.

This article has been peer reviewed.

Correspondence to: Chung Sim Lim, cslim@doctors.org.uk CMAJ 2014. DOI:10.1503 /cmaj.131281

\section{- KeY POINTS}

- Graduated compression stockings vary in terms of degree of compression, length, textile material, colour, design and manufacturer.

- There is high-quality evidence for the use of the stockings in patients with chronic venous insufficiency, especially those with ulcers.

- Graduated compression stockings need to be measured and fitted properly.

- Although use of the stockings is usually safe, several adverse effects and complications, including allergic reaction and skin necrosis, have been reported.

- Clinicians often underestimate the importance of patients' compliance with compression therapy, which is known to be low.

- Addressing patients' concerns, providing adequate information and reassurance, changing the stocking material or lowering the degree of compression usually helps improve compliance. 
cations. Poorly fitting stockings can cause discomfort and, at worst, pressure necrosis. The use of graduated compression stockings on legs with impaired arterial flow can worsen ischemia. ${ }^{6,7}$ Patients who are allergic to the stocking material may develop contact dermatitis, skin discoloration and blistering. For example, in CLOTS (Clots in Legs or Stockings after Stroke) trial 1 - a multicentre randomized controlled trial (RCT) that assessed the effectiveness of thigh-length graduated compression stockings to reduce the risk of deep vein thrombosis after stroke in about 2500 patients - skin breaks, ulcers, blisters and necrosis were significantly more common among patients wearing the stockings than among those not wearing them $(5.1 \%$ v. $1.3 \%) .{ }^{8}$ Textile properties, including fabric roughness, thermoregulation and dye, may contribute to skin reactions. ${ }^{9}$

Many complications of graduated compression stockings are preventable if patients are assessed, measured and fitted appropriately. If complications occur, many are easily overcome by refitting the stockings, changing the material, applying an emollient and reducing the degree of compression. Accurate measurement of the limb diameter that conforms to the stocking manufacturer's guidelines should be performed by a trained health care professional, often a nurse.

\section{Noncompliance}

The noncompliance rate for graduated compression stockings has been reported to be $30 \%-$
$65 \%{ }^{10,11}$ Commonly cited reasons include pain, discomfort, difficulty donning the stockings, perceived ineffectiveness, excessive heat, skin irritation, cost and appearance. ${ }^{6,10,12}$ Clinicians should ask their patients why the stockings are not being used, because many of these factors are easily amenable by simply changing the stocking material, lowering the degree of compression or providing adequate information and reassurance to patients. Box 4 shows the information that we believe should be given to patients when prescribing graduated compression stockings.

\section{What are the clinical indications?}

\section{Primary chronic venous disease}

Patients with chronic venous disease may present with symptoms and signs of leg pain, heaviness, itchiness, edema, eczema, lipodermatosclerosis, thrombophlebitis and ulceration. ${ }^{13,14}$ Chronic venous disease is often classified using the CEAP (clinical, etiologic, anatomic and pathophysiologic) system. ${ }^{13}$ Table 1 shows the simplified CEAP system in which only the highest clinical class is stated. ${ }^{1}$

The use of compression is a conservative measure. It does not cure varicosities, although it may relieve symptoms and prevent deterioration. ${ }^{15}$ Many studies that investigated the effectiveness of graduated compression stockings in patients of all CEAP classes reported improvement in symptoms such as pain and swelling and in activity

\section{Box 1: Types of compression stockings}

\section{Graduated or medical compression stockings}

- Graduated compression stockings exert the greatest degree of compression at the ankle, and the level of compression gradually decreases up the garment

- They are often used to treat chronic venous disease and edema

- They are designed for ambulatory patients and are manufactured under strict medical and technical specifications, including consistency and durability, to provide a specific level of ankle pressure and graduation of compression

\section{Antiembolism stockings}

- Antiembolism stockings are used to reduce the risk of deep vein thrombosis

- Like graduation compression stockings, they provide gradient compression

- They are designed for bedridden patients and do not meet the technical specifications for use by ambulatory patients

- Although the terms "antiembolism stockings" and "graduated compression hosiery" are often used interchangeably and both types of stockings offer graduated compression, they have different levels of compression and indications

\section{Nonmedical support hosiery}

- Nonmedical support hosiery, including flight socks and elastic support stockings, are often used to provide relief for tired, heavy and aching legs

- They usually exert considerably less compression than graduated compression stockings

- The compression is uniform and not graduated

- They do not need to meet the strict medical and technical specifications as those of graduated compression stockings

- They can often be bought over the counter without a prescription 
levels and well-being. ${ }^{1}$ A multicentre RCT assessing the efficacy of graduated compression stockings (pressure 10-15 $\mathrm{mm} \mathrm{Hg}$ ) in 125 female patients with CEAP class $\mathrm{C}_{1}-\mathrm{C}_{3}$ reported a significant improvement in relieving global painful discomfort and quality-of-life criteria with the stockings compared with placebo stockings. ${ }^{16}$ However, these findings were limited by the recruitment of a heterogeneous group of patients, and no subgroup analysis was performed. ${ }^{6,11}$

\section{Uncomplicated varicose veins}

The evidence for the benefit of graduated compression stockings in uncomplicated varicose veins was equivocal, and the published literature was often contradictory and had methodologic flaws.

A Cochrane systematic review of graduated compression stockings for the initial treatment of varicosities in patients without venous ulceration (CEAP class $\mathrm{C}_{2}-\mathrm{C}_{4}$ ) included seven RCTs $(n=$ 356). ${ }^{11}$ Although the participants' symptoms and physiologic measures subjectively improved in all of the studies when graduated compression stockings were worn, there was a risk of bias because the assessments were not made by comparing one randomized arm with a control arm. Another systematic review of graduated compression stockings for uncomplicated varicosities identified 25 studies. ${ }^{6}$ Wearing the stockings improved symptom management, but the findings may have been confounded by the exclusion of a high number of noncompliant patients within the trials. The review also found no evidence that wearing the stockings slowed the progression or prevented the recurrence of varicose veins.

Consensus statements from the Society for Vascular Surgery/American Venous Forum Guideline Committee cautiously recommended the use of graduated compression stockings in this group of patients and accepted that the evidence supporting this recommendation was limited. ${ }^{1}$ Recently, the National Institute for Health and Care Excellence (NICE) in the United Kingdom recommended against the use of graduated compression stockings to treat varicosities unless interventional treatment is unsuitable. ${ }^{17}$

Some studies reported that low-compression stockings were as effective as high-compression stockings but had a better compliance rate. ${ }^{16,18} \mathrm{~A}$ meta-analysis of $11 \mathrm{RCT}$ reported that compression of 15-20 mm Hg showed beneficial effects on edema and symptoms, as compared with compression of less than $10 \mathrm{~mm} \mathrm{Hg}$ or no compression; there was no difference between compression of 10-20 mm Hg and greater than $20 \mathrm{~mm} \mathrm{Hg.}{ }^{19}$

There was insufficient evidence to determine which length of graduated compression stocking (below knee or thigh length) was most beneficial., ${ }^{6,11}$

\section{Chronic venous insufficiency}

Although we found no RCT that compared compression with no compression in patients with venous skin changes (CEAP class $\mathrm{C}_{4}$ ), it is generally accepted that the management of such patients should include graduated compression stockings if tolerated. ${ }^{1,20}$ There is high-quality

\section{Box 2: Summary of the literature review}

We searched PubMed to identify peer-reviewed original research articles, meta-analyses and reviews (the last search was on July 31, 2013, with no restriction to publication dates). Search terms were "compression stockings," "compression hosiery" and "elastic stockings." We included articles if the studies involved humans, the article was published in English and the topic related to venous thromboembolism, venous disease, venous insufficiency or ulcer, superficial thrombophlebitis, varicose veins, leg lymphedema, pregnancy, postthrombotic syndrome or chronic edema. We manually searched bibliographies of reviewed articles to expand the literature search. In addition, we consulted clinical practice guidelines.
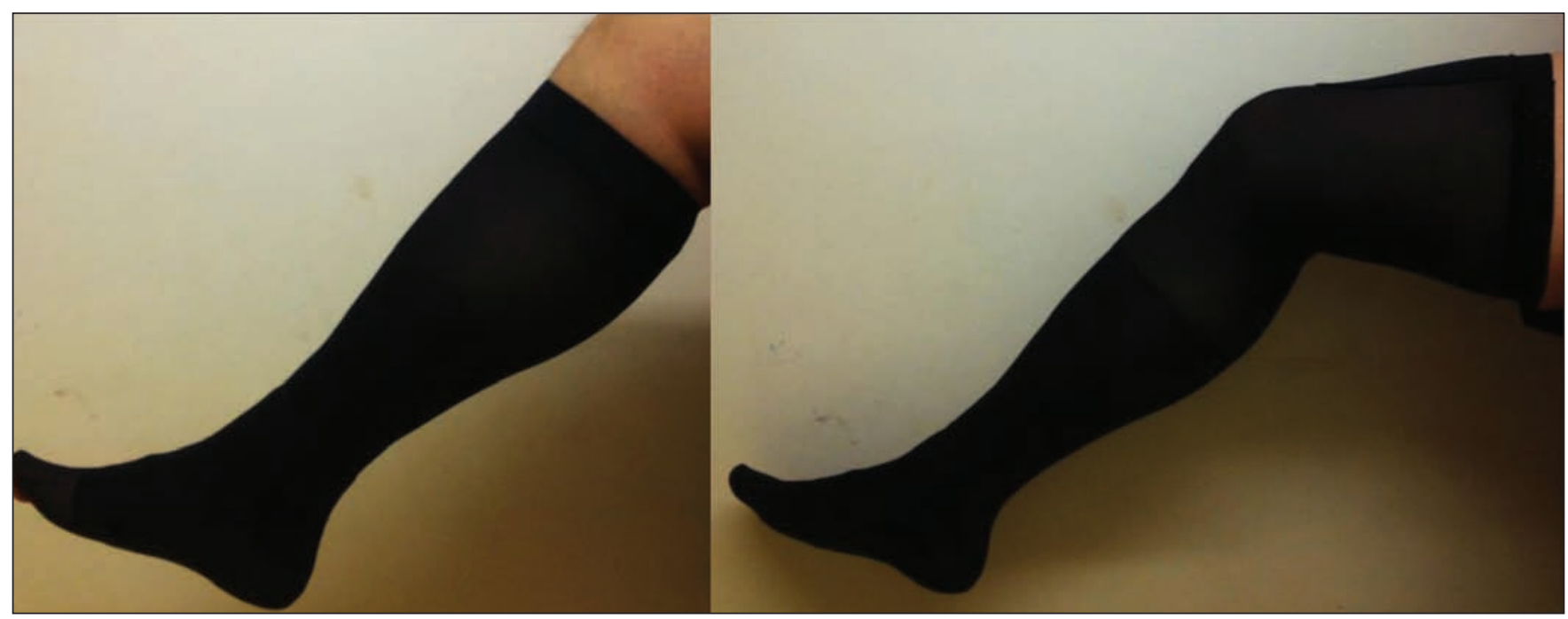

Figure 1: Below-knee and thigh-length compression stockings. 
evidence that venous ulcers heal more rapidly with than without compression therapy.,21,22

Patients with venous ulcers are often treated with compression bandages. However, there is some evidence that graduated compression stockings are equally effective..$^{22,23} \mathrm{~A}$ meta-analysis of eight RCTs $(n=692)$ reported that the proportion of ulcers that healed was significantly higher with graduated compression stockings than with bandages $(62.7 \%$ v. $46.6 \%){ }^{23}$ The average time to ulcer healing was also significantly shorter with the stockings, by three weeks. Graduated compression stockings may also be associated with less pain than bandages are. ${ }^{21,23}$

There is evidence that high-compression (30-40 $\mathrm{mm} \mathrm{Hg}$ ) stockings are more effective than medium- and low-compression stockings in promoting venous ulcer healing and preventing recurrence. ${ }^{22,24} \mathrm{~A}$ Cochrane systematic review of four RCTs $(n=979)$ concluded that there is some evidence, although not strong, that graduated compression stockings may prevent recurrence of venous ulcers and that highcompression stockings may be more efficacious than those with moderate compression. ${ }^{24}$

\section{Postsurgical or interventional treatment of varicose veins}

Compression therapy in the form of bandages or stockings is widely used immediately after surgical or interventional treatment of varicose veins, although few RCTs have assessed this. ${ }^{25,26}$ For example, compression after sclerotherapy has been shown to reduce the formation of thrombi and to prevent pigmentation and matting by minimizing inflammation and angiogenesis. ${ }^{27}$ However, one study that randomly assigned 60 patients to wear graduated compression stockings for three weeks or to go without compression after ultrasoundguided foam sclerotherapy found no difference in efficacy, adverse effects, satisfaction scores, symptoms and quality of life between the two groups. ${ }^{26}$ We found no evidence that one form of compression was better than another, although graduated compression stockings may be better accepted by patients than bandages. ${ }^{25}$

\section{Prevention of venous thromboembolism}

\section{Hospital patients}

Many studies that assessed the role of graduated compression stockings in preventing venous thromboembolism were often small, used asymptomatic deep vein thrombosis detected through screening tests as the study outcome and focused on surgical patients. ${ }^{28}$

A systematic review of graduated compression stockings for the prevention of deep vein thrombosis in patients admitted to hospital because of conditions other than stroke identified $18 \mathrm{RCTs} .^{29}$

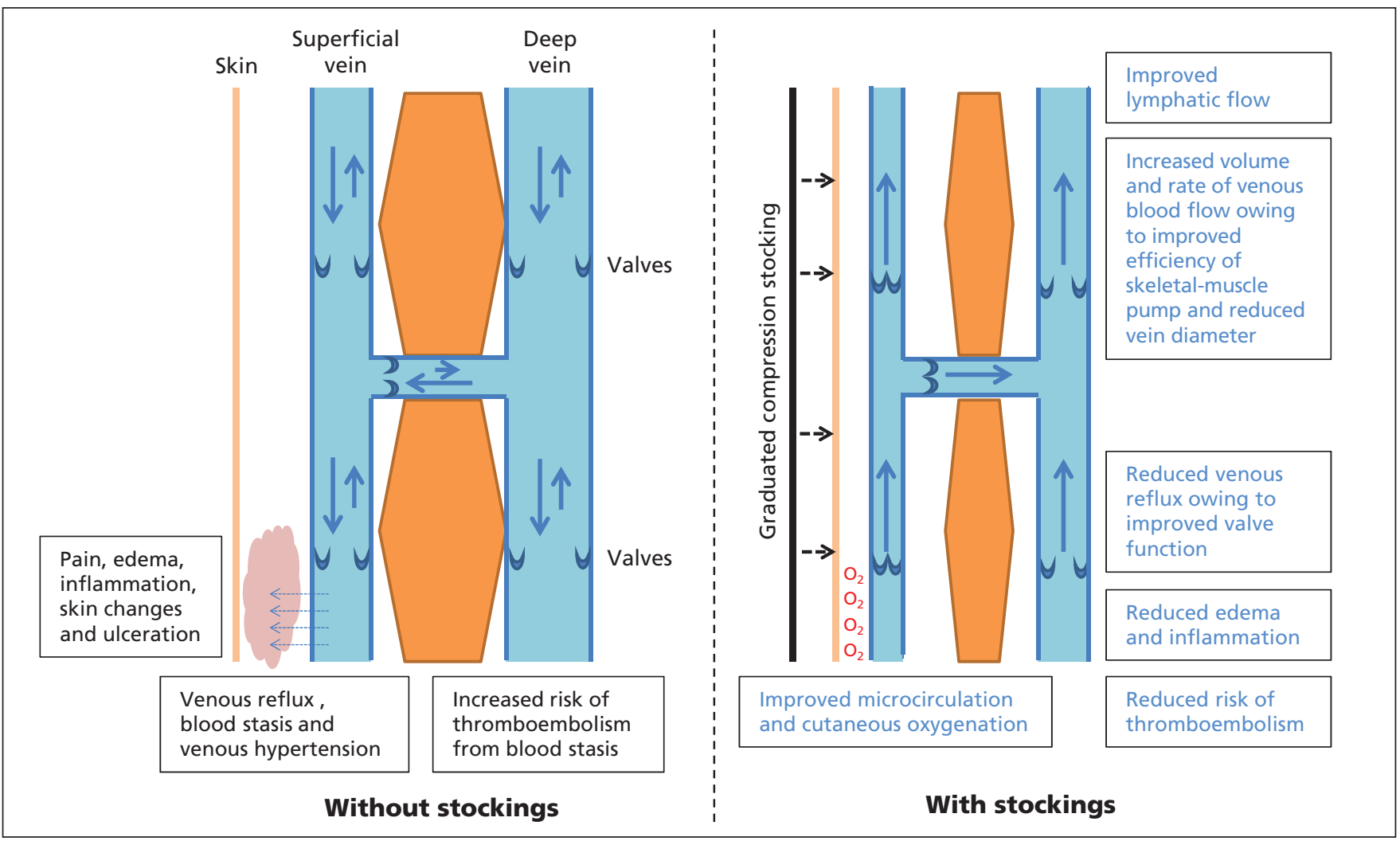

Figure 2: The mechanisms of action of graduated compression stockings. 
Graduated compression stockings were used alone or in combination with another form of prophylaxis (e.g., heparin, acetylsalicylic acid and sequential compression). All but one of the RCTs assessed surgical patients. Deep vein thrombosis was diagnosed mostly through screening with ultrasonography, venography or isotope studies. Deep vein thrombosis developed in $13 \%$ of patients given graduated compression stockings, as compared with $26 \%$ of those with no stockings. In the trials in which stockings were given in combination with another prophylactic method, deep vein thrombosis developed in $4 \%$ of patients given the stockings plus another method, as compared with $16 \%$ of those given the other method alone. It was concluded that graduated compression stockings were effective in reducing the risk of deep vein thrombosis among patients in hospital, especially when used with another method of prophylaxis. ${ }^{29}$

In CLOTS trial 1, symptomatic and asymptomatic deep vein thrombosis occurred in 126 $(10.0 \%)$ patients wearing graduated compression stockings and in 133 (10.5\%) not wearing them, for a nonsignificant absolute reduction in risk of $0.5 \%$ (95\% confidence interval $[\mathrm{CI}]-1.9 \%$ to $2.9 \%)^{8}$

These findings call into question whether graduated compression stockings prevent venous thromboembolism and support the need for further trials evaluating their efficacy in medical and surgical patients. ${ }^{28}$

\section{Travel-related venous thromboembolism}

One meta-analysis reported that travel of long duration is associated with a three-fold increased risk of venous thromboembolism, with a doseresponse association of $18 \%$ increased risk per two-hour increase in duration..$^{30}$ In one study, 231 airline passengers aged over 50 years with no history of venous thromboembolism were randomly assigned to wear class $1(20-30 \mathrm{~mm} \mathrm{Hg})$ below-knee graduated compression stockings or no stockings in journeys lasting more than eight hours. ${ }^{31}$ None of the passengers who wore the stockings had deep vein thrombosis, whereas 12 of 116 who did not wear stockings had asymptomatic deep calf vein thrombosis identified through screening with D-dimer assay and duplex ultrasonography.

A systematic review of 10 RCTs concluded that wearing graduated compression stockings may reduce the incidence of asymptomatic deep vein thrombosis and leg edema in airline passengers. However, none of the trials was large enough to assess the effect of graduated compression stockings on death, pulmonary embolus or symptomatic deep vein thrombosis. ${ }^{32}$

\section{Postthrombotic syndrome}

\section{Prevention}

A common complication of deep vein thrombosis, postthrombotic syndrome is characterized by clinical features ranging from leg pain, swelling or minor skin changes to severe ulceration. ${ }^{33,34} \mathrm{~A}$ meta-analysis of five RCTs showed that severe postthrombotic syndrome occurred in $5 \%$ of patients given graduated compression stockings and $12 \%$ of patients with no compression (relative risk $0.38,95 \%$ CI 0.22 to 0.68$).{ }^{35}$ Postthrombotic syndrome of any severity occurred in $26 \%$ with stockings and $46 \%$ without stockings (relative risk $0.54,95 \% \mathrm{CI} 0.44$ to 0.67 ). ${ }^{35}$

In the UK, NICE recommends that patients with proximal deep vein thrombosis wear belowknee graduated compression stockings with an ankle pressure greater than $23 \mathrm{~mm} \mathrm{Hg}$ for at least two years beginning a week after diagnosis or when swelling is reduced sufficiently, and if there is no contraindication. ${ }^{36}$ The recommendation was based on evidence from two RCTs. ${ }^{37,38}$ Both studies found that about half of the patients with a first episode of proximal deep vein thrombosis

\section{Box 3: Contraindications to graduated} compression stockings ${ }^{6-9}$

- Suspected or proven peripheral arterial disease, including history of peripheral arterial bypass grafting

- Severe peripheral neuropathy or other cause of sensory impairment

- Allergy to stocking material

- Massive leg edema or pulmonary edema from congestive cardiac failure

- Local skin or soft-tissue condition, including recent skin graft, fragile "tissue paper" skin, gangrene, oozing dermatitis and severe cellulitis

- Extreme deformity of the leg, or unusual leg shape or size preventing correct fit

Box 4: Information to be given to patients

- The reason why graduated compression stockings have been prescribed

- The benefits of wearing them regularly

- How to apply them correctly

- How long to wear them each day

- When to take them off

- When to replace them

- Daily hygiene

- How to recognize potential problems

- What to do or whom to contact if problems occur 
had postthrombotic syndrome within two years, and graduated compression stockings decreased this rate by about $50 \%$. These studies showed a clinically important reduction in the incidence of postthrombotic syndrome (254 fewer per 1000, 95\% CI 172 to 311 fewer), although there were no comparative data on adverse events. ${ }^{36}$

A recent double-blind multicentre RCT (the SOX trial) involving 806 patients compared the effectiveness of compression and placebo stockings worn on affected legs daily for two years. It showed that graduated compression stockings did not prevent the occurrence or influence the severity of postthrombotic syndrome after a first proximal deep vein thrombosis. The cumulative incidence of the syndrome by 750 days was similar between the intervention and control groups $(14.2 \%$ and $12.7 \%) .{ }^{39}$

\section{Treatment}

A systematic review of RCTs on pharmacologic and compression therapies for postthrombotic syndrome reported that there was low-quality evidence to support the use of graduated compression stockings for treatment of the condition. ${ }^{34}$ This was based on two RCTs. ${ }^{40,41}$ In the first study, 35 patients with symptomatic postthrombotic syndrome a year after having proximal deep vein thrombosis were randomly assigned to wear graduated compression stockings $(30-40 \mathrm{~mm} \mathrm{Hg}$ ) or a matched placebo stocking. ${ }^{40}$ The proportion of patients with treatment failure did not differ significantly between the two groups (61\% and 59\%, respectively). In the second study, patients with postthrombotic syndrome were randomly assigned to wear belowknee graduated compression stockings (30$40 \mathrm{~mm} \mathrm{Hg}$ ) on the affected leg, to take hydroxy-

Table 1: Clinical classification of chronic venous disease according to the CEAP system ${ }^{1}$

\begin{tabular}{|ll|}
\hline Class & \multicolumn{1}{c|}{ Description } \\
\hline$C_{0}$ & $\begin{array}{l}\text { No visible or palpable signs of } \\
\text { venous disease }\end{array}$ \\
\hline$C_{1}$ & $\begin{array}{l}\text { Telangiectases or reticular veins } \\
C_{2}\end{array}$ \\
\hline$C_{3}$ & Varicose veins \\
\hline$C_{4 a}$ & Edema \\
\hline$C_{4 b}$ & $\begin{array}{l}\text { Ligmentation or eczema } \\
\text { blanche }\end{array}$ \\
\hline$C_{5}$ & Healed venous ulcer \\
\hline$C_{6}$ & Active venous ulcer \\
\hline $\begin{array}{l}\text { Note: CEAP }=\text { clinical, etiologic, anatomic and } \\
\text { pathophysiologic. }\end{array}$ \\
\hline
\end{tabular}

ethylrutoside (a venoactive drug) orally, or to use both interventions, for 12 months; there were 40 participants in each group. ${ }^{41}$ No clear differences were found in improvement or worsening of the postthrombotic syndrome between the groups.

\section{Lymphedema and chronic leg edema}

Lymphedema refers to conditions involving impaired lymphatic drainage causing chronic build-up of fluid and swelling in the limbs. The current international standard of care for lymphedema is formalized in a 2013 consensus document of the International Society of Lymphology. ${ }^{42}$

Treatment of lymphedema often includes complex decongestive therapy and generally involves a two-phase approach. The first phase is intensive reduction of swelling, consisting of skin care, manual massage or lymph drainage, exercises and compression typically with multilayered bandages. The second phase is the long-term maintenance of volume, which includes skin care, exercises, compression therapy, self-lymph drainage and, in some patients, pneumatic lymph drainage.

Graduated compression stockings are often used in the second phase to maintain long-term lymphedema reduction..$^{42}$ There is evidence that high-compression stockings $(30-40 \mathrm{~mm} \mathrm{Hg}$ ) are effective..$^{22}$ Generally, the highest level of compression $(20-60 \mathrm{~mm} \mathrm{Hg}$ ) that the patient can tolerate is likely to be the most beneficial. ${ }^{42}$ However, lower compression can be used for milder lymphedema or general leg edema. ${ }^{43}$

\section{Superficial thrombophlebitis}

Graduated compression stockings can be used as part of the management of superficial thrombophlebitis, which may include other topical therapy, anticoagulation, nonsteroidal anti-inflammatory drugs and surgery. Graduated compression stockings help to relieve local symptoms and may prevent extension of venous thrombosis. A systematic review reported that the combination of surgical treatment and use of graduated compression stock-

\section{Box 5: Unanswered questions}

- Is the use of graduated compression stockings, compared with no stockings, clinically beneficial and cost-effective as the initial treatment of varicose veins in patients without venous skin changes or ulceration?

- What is the optimal compression pressure for the prevention and treatment of chronic venous insufficiency?

- Which length of graduated compression stocking (below knee or thigh length) is more effective in preventing deep vein thrombosis, preventing postthrombotic syndrome and treating chronic venous insufficiency? 
ings was associated with a lower rate of venous thromboembolism and progression of superficial thrombophlebitis compared with stockings alone. ${ }^{44}$

\section{Pregnancy}

A nonrandomized trial described that graduated compression stockings may provide improvement of venous emptying and subjective alleviation of leg problems such as swelling, tiredness and pain in pregnant women. ${ }^{45} \mathrm{~A}$ small RCT reported that graduated compression stockings failed to prevent varicose veins but improved leg symptoms in pregnant women. ${ }^{46}$ A Cochrane systematic review concluded that graduated compression stockings do not appear to reduce leg edema in pregnant women. ${ }^{47}$

\section{Conclusion}

Although unanswered questions about the use of graduated compression stockings remain (Box 5), high-quality evidence supports their use by patients with chronic venous insufficiency, especially those with ulcers. There is evidence of low to moderate quality for the prophylactic effect of the stockings against deep vein thrombosis in medically ill patients, but low-quality evidence in general surgical and orthopedic patients. The latest evidence from a large multicentre RCT did not support the use of graduated compression stockings to prevent postthrombotic syndrome, and we found no evidence to support their use for treatment of the syndrome. Graduated compression stockings are effective during the long-term maintenance of volume in lymphedema. For superficial thrombophlebitis, there may be some benefit from wearing graduated compression stockings in combination with surgery. There is insufficient evidence to support their use during pregnancy.

When used, graduated compression stockings need to be measured and fitted properly. Patients also need to be informed of their indication and risks. Addressing patients' concerns, providing adequate information and reassurance, changing the stocking material or lowering the degree of compression usually helps improve compliance in our experience.

\section{References}

1. Gloviczki P, Comerota AJ, Dalsing MC, et al. The care of patients with varicose veins and associated chronic venous diseases: clinical practice guidelines of the Society for Vascular Surgery and the American Venous Forum. J Vasc Surg 2011; 53(Suppl):2S-48S.

2. Motykie GD, Caprini JA, Arcelus JI, et al. Evaluation of therapeutic compression stockings in the treatment of chronic venous insufficiency. Dermatol Surg 1999;25:116-20.

3. Moffatt C. Variability of pressure provided by sustained compression. Int Wound J 2008;5:259-65.

4. Agu O, Baker D, Seifalian AM. Effect of graduated compression stockings on limb oxygenation and venous function during exercise in patients with venous insufficiency. Vascular 2004;12:69-76.
5. Beidler SK, Douillet CD, Berndt DF, et al. Inflammatory cytokine levels in chronic venous insufficiency ulcer tissue before and after compression therapy. J Vasc Surg 2009;49:1013-20.

6. Palfreyman SJ, Michaels JA. A systematic review of compression hosiery for uncomplicated varicose veins. Phlebology 2009; 24(Suppl 1):13-33.

7. Callam MJ, Ruckley CV, Dale JJ, et al. Hazards of compression treatment of the leg: an estimate from Scottish surgeons. Br Med J (Clin Res Ed) 1987;295:1382.

8. Dennis M, Sandercock PA, Reid J, et al. Effectiveness of thighlength graduated compression stockings to reduce the risk of deep vein thrombosis after stroke (CLOTS trial 1): a multicentre, randomised controlled trial. Lancet 2009;373:1958-65.

9. Wollina U, Abdel-Naser MB, Verma S. Skin physiology and textiles - consideration of basic interactions. Curr Probl Dermatol 2006;33:1-16.

10. Raju S, Hollis K, Neglen P. Use of compression stockings in chronic venous disease: patient compliance and efficacy. Ann Vasc Surg 2007;21:790-5.

11. Shingler S, Robertson L, Boghossian S, et al. Compression stockings for the initial treatment of varicose veins in patients without venous ulceration. Cochrane Database Syst Rev 2011;(11): CD008819.

12. Ziaja D, Kocelak P, Chudek J, et al. Compliance with compression stockings in patients with chronic venous disorders. Phlebology 2011;26:353-60.

13. Bergan JJ, Schmid-Schonbein GW, Smith PD, et al. Chronic venous disease. N Engl J Med 2006;355:488-98.

14. Eberhardt RT, Raffetto JD. Chronic venous insufficiency. Circulation 2005;111:2398-409.

15. Gloviczki P, Gloviczki ML. Guidelines for the management of varicose veins. Phlebology 2012;27(Suppl 1):2-9.

16. Benigni JP, Sadoun S, Allaert FA, et al. Efficacy of class 1 elastic compression stockings in the early stages of chronic venous disease. A comparative study. Int Angiol 2003;22:383-92.

17. Varicose veins in the legs: the diagnosis and management of varicose veins. London (UK): National Institute for Health and Care Excellence; 2013. Available: www.nice.org.uk/guidance /index.jsp?action=byID\&o=14226 (accessed 2013 July 31).

18. Jungbeck C, Thulin I, Darenheim C, et al. Graduated compression treatment in patients with chronic venous insufficiency: a study comparing low and medium grade compression stockings. Phlebology 1997;12:142-5.

19. Amsler F, Blattler W. Compression therapy for occupational leg symptoms and chronic venous disorders - a meta-analysis of randomised controlled trials. Eur J Vasc Endovasc Surg 2008; 35:366-72.

20. Miteva M, Romanelli P, Kirsner RS. Lipodermatosclerosis. Dermatol Ther 2010;23:375-88.

21. O'Meara S, Cullum NA, Nelson EA. Compression for venous leg ulcers. Cochrane Database Syst Rev 2009;(1):CD000265.

22. Partsch H, Flour M, Smith PC. Indications for compression therapy in venous and lymphatic disease consensus based on experimental data and scientific evidence. Under the auspices of the IUP. Int Angiol 2008;27:193-219.

23. Amsler F, Willenberg T, Blattler W. In search of optimal compression therapy for venous leg ulcers: a meta-analysis of studies comparing diverse [corrected] bandages with specifically designed stockings. J Vasc Surg 2009;50:668-74.

24. Nelson EA, Bell-Syer SE. Compression for preventing recurrence of venous ulcers. Cochrane Database Syst Rev 2012;(8): CD002303.

25. Mariani F, Marone EM, Gasbarro V, et al. Multicenter randomized trial comparing compression with elastic stocking versus bandage after surgery for varicose veins. J Vasc Surg 2011;53:115-22.

26. Hamel-Desnos CM, Guias BJ, Desnos PR, et al. Foam sclerotherapy of the saphenous veins: randomised controlled trial with or without compression. Eur J Vasc Endovasc Surg 2010; 39:500-7.

27. Kern P, Ramelet AA, Wutschert R, et al. Compression after sclerotherapy for telangiectasias and reticular leg veins: a randomized controlled study. J Vasc Surg 2007;45:1212-6.

28. Kearon C, O'Donnell M. Graduated compression stockings to prevent venous thromboembolism in hospital: evidence from patients with acute stroke. Pol Arch Med Wewn 2011;121:40-3.

29. Sachdeva A, Dalton M, Amaragiri SV, et al. Elastic compression stockings for prevention of deep vein thrombosis. Cochrane Database Syst Rev 2010;(7):CD001484.

30. Chandra D, Parisini E, Mozaffarian D. Meta-analysis: travel and risk for venous thromboembolism. Ann Intern Med 2009;151: 180-90.

31. Scurr JH, Machin SJ, Bailey-King S, et al. Frequency and prevention of symptomless deep-vein thrombosis in long-haul flights: a randomised trial. Lancet 2001;357:1485-9. 
32. Clarke M, Hopewell S, Juszczak E, et al. Compression stockings for preventing deep vein thrombosis in airline passengers. Cochrane Database Syst Rev 2006;(2):CD004002.

33. Saedon M, Stansby G. Post-thrombotic syndrome: prevention is better than cure. Phlebology 2010;25(Suppl 1):14-9.

34. Cohen JM, Akl EA, Kahn SR. Pharmacologic and compression therapies for postthrombotic syndrome: a systematic review of randomized controlled trials. Chest 2012;141:308-20.

35. Musani MH, Matta F. Yaekoub YA, et al. Venous compression for prevention of postthrombotic syndrome: a meta-analysis. Am J Med 2010;123:735-40.

36. Venous thromboembolic diseases: the management of venous thromboembolic diseases and the role of thrombophilia testing. London (UK): National Institute for Health and Clinical Excellence; 2012. Available: guidance.nice.org.uk/CG144/ (accessed 2013 July 31).

37. Prandoni P, Lensing AW, Prins $\mathrm{MH}$, et al. Below-knee elastic compression stockings to prevent the post-thrombotic syndrome: a randomized, controlled trial. Ann Intern Med 2004;141:249-56.

38. Brandjes DP, Buller HR, Heijboer H, et al. Randomised trial of effect of compression stockings in patients with symptomatic proximal-vein thrombosis. Lancet 1997;349:759-62.

39. Kahn SR, Shapiro S, Wells PS, et al.; SOX Trial Investigators. Compression stockings to prevent post-thrombotic syndrome: a randomised placebo-controlled trial. Lancet 2014;383:880-8.

40. Ginsberg JS, Hirsh J, Julian J, et al. Prevention and treatment of postphlebitic syndrome: results of a 3-part study. Arch Intern Med 2001;161:2105-9.

41. Prandoni P. Elastic stockings, hydroxyethylrutosides or both for the treatment of post-thrombotic syndrome. Thromb Haemost 2005; $93: 183-5$

42. International Society of Lymphology. The diagnosis and treatment of peripheral lymphedema: 2013 consensus document of the International Society of Lymphology. Lymphology 2013;46:1-11.

43. Lay-Flurrie K. Use of compression hosiery in chronic oedema and lymphoedema. Br J Nurs 2011;20:418, 20, 22.

44. Di Nisio M, Wichers IM, Middeldorp S. Treatment for superficial thrombophlebitis of the leg. Cochrane Database Syst Rev 2012;(3):CD004982.

45. Nilsson L, Austrell C, Norgren L. Venous function during late pregnancy, the effect of elastic compression hosiery. Vasa 1992; 21:203-5.

46. Thaler E, Huch R, Huch A, et al. Compression stockings prophylaxis of emergent varicose veins in pregnancy: a prospective randomised controlled study. Swiss Med Wkly 2001;131:659-62.

47. Bamigboye AA, Smyth R. Interventions for varicose veins and leg oedema in pregnancy. Cochrane Database Syst Rev 2007; (1):CD001066.

Affiliation: Department of Surgery and Cancer, Faculty of Medicine, Imperial College London and Charing Cross Hospital, London, UK

Contributors: Both authors contributed to the design and conception and to the drafting and revising of the article. Both gave final approval of the version to be published and act as guarantors of the work.

\section{Resources for clinicians and patients}

For clinicians

- UK National Institute for Health and Care Excellence (NICE):

- Guideline on reducing the risk of venous thromboembolism (deep vein thrombosis and pulmonary embolism) in patients admitted to hospital [clinical guideline 92] (http://guidance.nice.org.uk/CG92)

- Guideline on the management of venous thromboembolic diseases and the role of thrombophilia testing [clinical guideline 144] (http://guidance.nice.org.uk/CG144)

- Guideline on varicose veins in the legs: the diagnosis and management of varicose veins [clinical guideline CG168] (www.nice.org.uk/guidance/index.jsp?action=byID\&o=14226)

- Cochrane Collaboration reviews (www.cochrane.org/cochrane-reviews): up-to-date systematic reviews on the clinical evidence of graduated compression stockings for the prevention and treatment of venous thromboembolism and chronic venous disease

- NICE Clinical Knowledge Summaries on compression stockings (http://cks.nice.org.uk/compressionstockings\#!topicsummary): a summary of the background information and use of compression stockings, and the current evidence base

- Phlebology: the Journal of Venous Disease (http://phl.sagepub.com): up-to-date original research articles, reviews and clinical guidelines on venous and lymphatic diseases, including management with compression therapy

For patients

- NHS Choices (www.nhs.uk): general information about compression stockings and chronic venous disease

- Circulation Foundation (www.circulationfoundation.org.uk): downloadable patient leaflets and newsletters on venous and lymphatic disease

- Compression therapy for venous disorders and venous ulceration (chapter 13 of Vein Handbook), American Venous Forum (www.veinforum.org/patients/vein-handbook/chapter-13-compression-therapy -for-venous-disorders-and-venous-ulceration) 